\title{
Bus Impact on the Inductance Distribution of Electromagnetic Launchers
}

\author{
Nail Tosun (D. Student Member, IEEE, Anıl Civil, Ahmet Yasin Oruç, Baran Yıldırım, Bekir Mert Özceylan, \\ Emre Burak Yurdakul, Evren Tan, Ferhat Yurdakonar, Hüseyin Akdemir, İbrahim Güngen, \\ Mustafa Karagöz, Member, IEEE, Özgur Cavbozar, Rasih Hakan Demirkol, Ulaş Göçmen, \\ and Ozan Keysan (ID), Member, IEEE
}

\begin{abstract}
Simulations are crucial in the electromagnetic launcher (EML) researches on account of extreme physical conditions. More energy into the system adds weight to the model's accuracy as the operation risk rises. In this paper, the electromagnetic impact of the bus structure is discovered in a recently developed EMFY-3 electromagnetic launcher, is presented. An H-shaped bus structure is used for current injection. However, experiments showed that the H-shaped bus changes inductance calculations. A careful examination is made to reveal the physical reasoning of the bus impact. We hypothesize that the rail portion surrounded with bus geometry has less inductance than the rest due to the eddy current created by rail current transients, which should be calculated carefully through numerical calculations, i.e., 3-D Finite Element Method (FEM). Two different simulation models were constructed to test the hypothesis. Moreover, rail currents, breech, and muzzle voltages are measured to investigate electromagnetic calculations. Results showed a good agreement with experiments where the bus structure was modeled explicitly. That aspect showed that the bus structure should be well-examined when multiple PPS are connected.
\end{abstract}

Index Terms-Electromagnetic launchers (EMLs), finite element (FE) analysis, pulsed-power supply (PPS), railgun, transient inductance, velocity skin effect (VSE).

\section{INTRODUCTION}

A T ASELSAN Inc., EMLs are examined in the military context since 2014 [1]-[7]. ASELSAN's most powerful EML, EMFY-3, reached 2.91 MJ muzzle energy, at 36\% efficiency, with an 8 MJ PPS in the ASELSAN's Electromagnetic Launch Laboratory. These experiments are demonstrated in the previous article. EMFY-3 launcher is illustrated in Fig. 1, and geometric parameters are in Table I]

Multiple capacitor-based modules are combined in parallel to provide an $8 \mathrm{MJ}$ input electrical energy. Each unit's triggering time influences the rail current waveform. A flattop rail current is desirable to reduce eddy current losses, inductive voltage oscillations, and preferable contact forces. The relationship between rail current waveform and the set of triggering times should be programmable in order to operate EML properly. Some studies use evolutionary algorithms (EA) to evaluate triggering times, considering the relationship is non-programmable. However, as Zhang et. al. stated that for a given magnitude of flat rail current, the set of triggering time is unique and can be calculated iteratively [8], [9]. We also used an iterative algorithm to evaluate the set of triggering times, considering the shape of rail current and muzzle velocity [10]. However, it should be noted that these calculations are depending on the model's accuracy heavily. Therefore, PPS circuity and the EML should be modeled precisely.

In contrast to PPS circuity, electromagnetic modeling of the EML is challenging in many aspects. For example, the

N. Tosun, and O. Keysan are with Middle East Technical University, Department of Electrical and Electronics Engineering, Ankara, Turkey. Email keysan@metu.edu.tr

A. Civil, A. Oruc, B. Yıldırım, B. Yurdakul, E. Tan,F. Yurdakonar, H. Akdemir, H. Demirkol, İ. Gungen, M. Özceylan, M. Karagöz, Ö. Cavbozar, and U. Göçmen are with ASELSAN Inc., Ankara 06370, Turkey (e-mail: mkaragoz@aselsan.com.tr).

Corresponding Author: Ozan Keysan, keysan@metu.edu.tr physical quantities of EML, such as its inductance, and resistance, are dynamic. They are influenced by armature position and velocity, the electrical excitation frequency, and complex contact states. Many efforts can be found in the literature to enhance simulation accuracy of EMLs. They can be classified into three:

\section{1) Pure lumped circuit method ( $p L C M$ )}

They are constructed with some dynamic circuit elements, i.e., resistance and inductance gradients related to launching dynamics [11]-[13]. Dynamic parameters can be calculated analytically, or they can be extracted from numerical tools. As the simulation model has one dimension, the strategy has the least computational effort.

2) Pure Finite Element Method (pFEM)

pFEM prefers to solve complete EML geometry in the electromagnetic FEM. As EMLs have a high aspect ratio (thinlong rails), such an approach is computationally expensive. Moreover, commercial FEM tools can not model 3-D sliding contact [14]; thus special FEM codes are required [15]-[17].

3) FEM-assisted lumped circuit method

This strategy middle way between pLCM and pFEM; thus, it can be called a hybrid method. For example, the computational load of the pFEM can be diminished by a co-simulated LCM which covers the effect of the movement $[5]-[7]$.

We used these sets of triggering times to conduct EMFY3 experiments; however, there are some mismatches with simulations. Especially at the initial stages, rail currents are underestimated, which results in higher experimental peak currents. It is dangerous to underestimate peak current, as EML is limited with maximum linear current density [18], [19]. After investigations, we discover that the mismatches happen due to the bus geometry. This structure is conductive, and it blocks the rail's magnetic field when the rail current is changing. As the magnetic field can not diffuse due to bus' eddy currents, the rail portion inside to bus structure has 
TABLE I

GeOMETRIC PARAMETERS OF THE LAUNCHER.

\begin{tabular}{lc}
\hline Rail Height & $50 \mathrm{~mm}$ \\
Rail Separation & $75 \mathrm{~mm}$ \\
Rail Length & $6.1 \mathrm{~m}$ \\
\hline
\end{tabular}

less inductance. Since the initial model does not consider this effect, the barrel's inductance is overestimated, concluding less rail current than actual values at the initial stages.

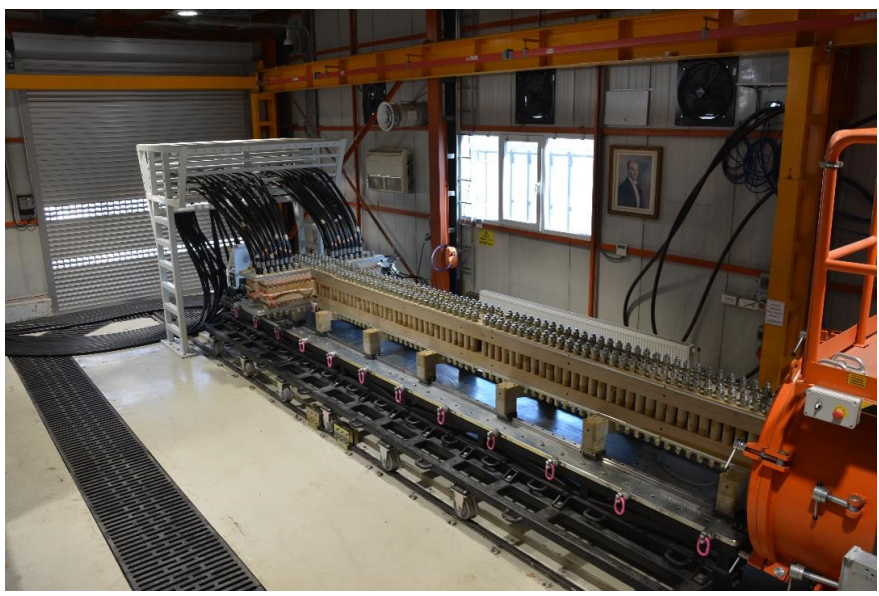

Fig. 1. EMFY-3 Launcher at the ASELSAN's Electromagnetic Launch Laboratory. More details about the laboratory can be found in [4].

In this study, a new EML modeling strategy enhanced with the bus' inductance effect is introduced. 3-D Finite Element Method (FEM) models used to calculate bus inductance, propulsive inductance gradient $\mathrm{L}_{\mathrm{pr}}^{\prime}$, or other characteristic parameters.These parameters are imported to the 1-D model to compare with experimental findings. Moreover, a control method where the bus impact is excluded is proposed in order to investigate its influence. The results showed that the bus structure affect the inductance of the system significantly, where peak rail currents, and muzzle energies calculations improved $5.71 \%$, and $2.40 \%$ in average respectively.

\section{Simulation Models}

Simulations are essential for the design and analysis procedure of EML as they operate in extreme physical conditions; a few MA current excitations, several hundred rail pressures, material phase changes, etc. Moreover, electromagnetic analysis of EML is a challenging topic, as there is no consensus on the methodology. The 3-D FEM is an excellent choice as the calculations are geometry dependent; however electromagnetic formulations in 3-D FEM has limitations due to sliding electrical contact. EML strategies are illustrated in Fig. 2. In this paper, models are constructed using pLCM approach due to its simplicity and computational efficiency. However, models parameters are estimated using 3-D FEM simulations.

In this section, the main focus is the investigate the influence of bus geometry on EML. In this regard, two simulation models are built; the control method and the proposed method. The proposed method takes into bus's inductance, unlike the control method. As these models differ at a single point, the control method creates a reference level to investigate the phenomena.
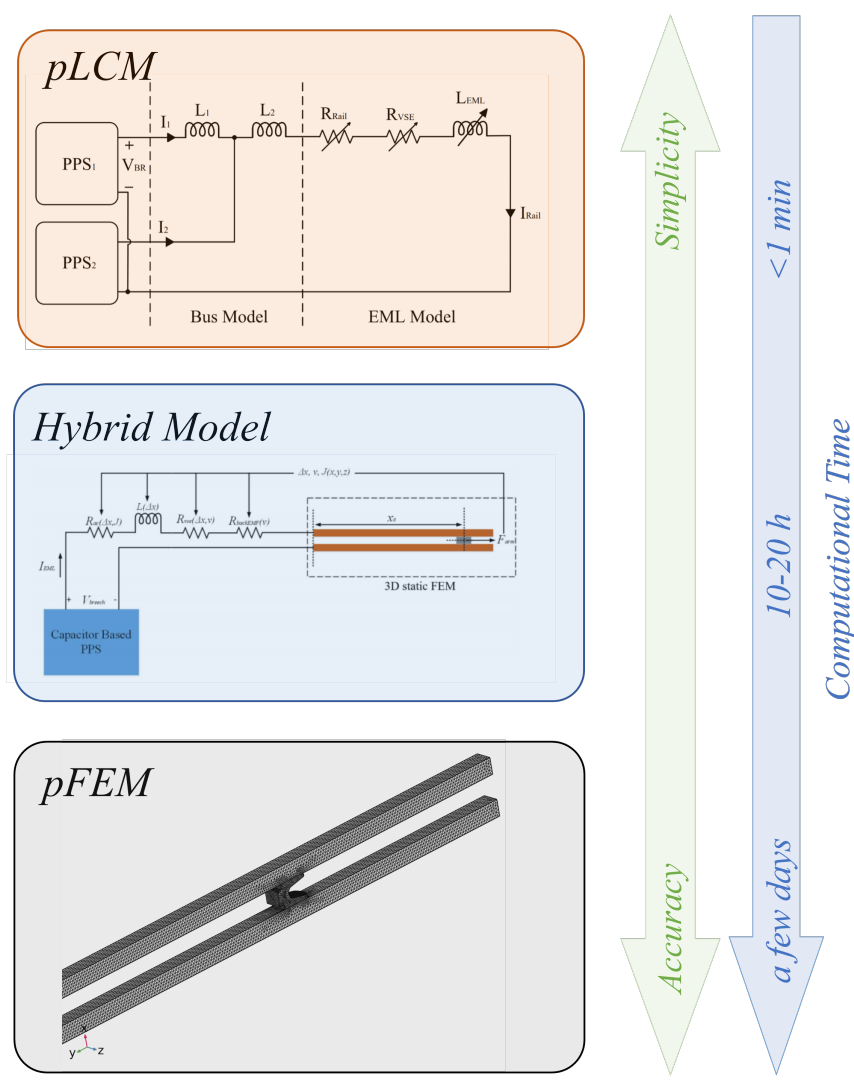

Fig. 2. EML simulation strategies.

The containment structure surrounds rails. If the containment material is not conductive, this structure can be modeled as air to simply the model. However, when the bus geometry is close to rails and covers a significant portion, it is essential to cover this geometry. As the bus connected with rails, magnetic field density distribution is disturbed due to eddy currents. Thus these two region's inductance should be modeled individually, not from a single parameters i.e. $\mathrm{L}^{\prime}$. This eddy current effect is called bus impact. This phenomenon is illustrated in Fig. 3

From the electrical point of view, an EML can be expressed as series-connected variable resistance and inductance as in Fig. 4. The inductance of the launcher depends on the position of the armature; its resistance depends on both the position and velocity of the armature as velocity skin effect (VSE) should be considered which requires mechanical states to be calculated continuously.

The control method is the simulation model used before the experiments; thus, it excludes the phenomenon. On the other hand, the proposed method includes bus' inductance, which helps to increase the model's accuracy. These two models also have common points, i.e., they use the same kine-mechanical calculations. Thus, these points are explained first, then the differences are explained in the following subsections in detail. 


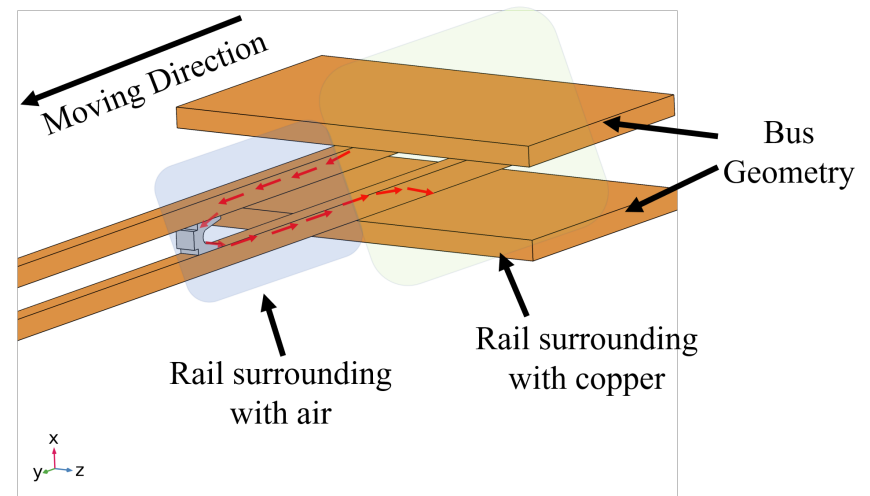

Fig. 3. The bus impact phenomenon. Red arrows indicate the current direction. The moving direction of the armature is specified as well. Two regions are illustrated with respect to inductance regions with colors. The blue region is surrounded with air, whereas green region is enclosed by bus geometry. As the bus is conductive, green region's magnetic field distribution affected by eddy currents at the bus.

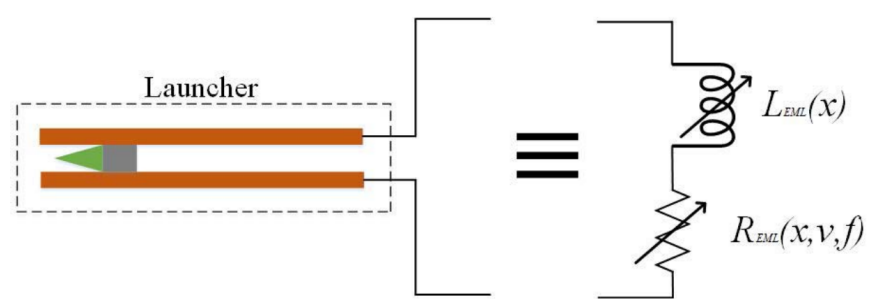

Fig. 4. Electromagnetic launcher can be modeled as series connected variable resistance and inductance.

\section{A. Common Features}

\section{1) EML modeling}

The electromagnetic launcher can be considered a one turn coil with a time-dependent inductance.

$$
\Phi(t)=\lambda(t)=L(t) I(t)
$$

The electromotive force (EMF) can be calculated using Lenz's Law.

$$
\epsilon(t)=\frac{d \lambda(t)}{d t}=\frac{d L(t)}{d t} I(t)+L(t) \frac{d I(t)}{d t}
$$

The second term in (13) is the voltage induced due to rail current transients. As EML inductance increases with the armature movement, as shown in (14). The inductance gradient can be calculated with 3-D FE, using flux-counting method as demonstrated in [6].

$$
L(t)=L^{\prime} \Delta x(t)
$$

The rail resistance variation can be calculated similarly as in (15). However, (15) does not reflect velocity skin effect (VSE) which is a dominant phenomena, where the armature velocity exceeds $500 \mathrm{~m} / \mathrm{s}$. VSE resistance, $R_{\mathrm{vse}}$, due to current diffusion in the rails when the armature is at some position $x$ as in (16) where $w$ is the rail width, $\rho_{\text {rail }}$ is the resistivity of the rail material, and $v_{c}$ is the constant velocity [20]. For a linearly increasing velocity, $v_{c}$ is one-half the instantaneous velocity $v$.

$$
\begin{gathered}
R_{\text {rail }}(t)=R_{\text {rail }}^{\prime} \Delta x(t) \\
R_{\text {vse }}=\frac{1}{w} \sqrt{\frac{\rho_{\text {rail }} \mu_{0}}{\pi}} \sqrt{x v_{c}}
\end{gathered}
$$

\section{2) Pulse Power Supply Modeling}

In EML applications, pulse power supplies (PPS) are often capacitor-based parallel connected topologies. Multiple PPS modules are used to excite EMFY-3 launcher, each module having the schematic shown in Fig. $4 . \mathrm{L}_{\mathrm{C}}$ and $\mathrm{R}_{\mathrm{C}}$ represent equivalent series inductance (ESL) and equivalent series resistance (ESR) of the capacitors respectively. $R_{T}$ and $R_{D}$ are $\mathrm{ON}$ resistance of the thyristor and diode stacks. Pulse shaping inductor is per $L_{P P S}$ with its ESR R $R_{P P S}$. As each module's cable varies in length, they need to be modelled individually with their inductance and resistance, $\mathrm{L}_{\text {cable }}$, and $\mathrm{R}_{\text {cable }}$ values. The PPS module model is showed in Fig. 4.

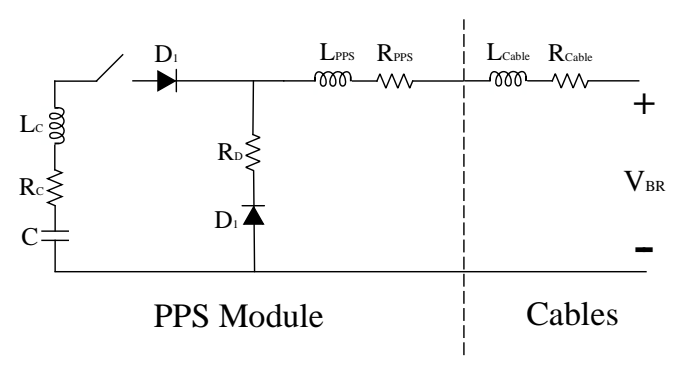

Fig. 5. The PPS module model.

\section{3) Kinemechanical calculations}

Propulsive force on the armature denoted as $\vec{F}_{p r}$ is calculated using propulsive inductance gradient, $\mathrm{L}_{\mathrm{pr}}^{\prime}$, and rail current $I_{\text {rail }}$ as in (1).

$$
\vec{F}_{p r}=\frac{L_{p r}^{\prime} I_{r a i l}^{2}}{2}
$$

However, the $\vec{F}_{p r}$ is not the only force that acts on the armature. Friction and drag forces, denoted as $\vec{F}_{\text {fric }}$ and $\vec{F}_{\text {drag }}$ slow down the movement as in $77 . \vec{F}_{\text {fric }}$ can be modelled as in (8) [21] where $\mu_{d}$ and $\mu_{s}$ are dynamic and static friction coefficients respectively. $\zeta$ is the friction damping factor, and $\vec{F}_{C}$ is the contact force between the rails and the armature.

$$
\begin{gathered}
\vec{F}_{n e t}=\max \left(0, \vec{F}_{p r}-\vec{F}_{f r i c}-\vec{F}_{d r a g}\right) \\
\vec{F}_{f r i c}=\left(\mu_{d}+\left(\mu_{s}-\mu_{d}\right) e^{\zeta-v}\right) \vec{F}_{C}
\end{gathered}
$$

Aerodynamic drag can be modeled as in (9). $\mathrm{C}_{\mathrm{d}}$ is the drag coefficient, $A_{l p}$ is the area that frontier to the air, $\rho_{\text {air }}$ is the density of air. There are no drag forces due to eddy current in the containment as the EMFY-3 has a non-metallic containment.

$$
\vec{F}_{\text {drag }}=\frac{1}{2} C_{d} A_{l p} \rho_{a i r} v_{\text {arm }}^{2}
$$


Acceleration of the launch package can be expressed as in 10 where $m_{l p}$ is the mass of the launch package. Other kine-mechanical equations are presented from (6) to (9) where $\mathrm{T}_{\text {exit }}$ is the exit moment of the armature, $\mathrm{X}_{\text {pre }}$ is the pre-load position, and $\mathrm{x}_{\text {rail }}$ is the rail length.

$$
\begin{gathered}
\vec{F}_{\text {net }}=m_{l p} \vec{a}_{l p} \\
\vec{a}_{l p}=\frac{L^{\prime} I_{\text {rail }}^{2}}{2 m_{l a}} \\
\vec{v}_{\text {arm }}=\int_{0}^{T_{\text {exit }}} \frac{L^{\prime} I_{\text {rail }}^{2}}{2 m_{\text {la }}} d t \\
\vec{x}_{\text {arm }}=\int_{0}^{T_{\text {exit }}} \int_{0}^{T_{\text {exit }}} \frac{L^{\prime} I_{\text {rail }}^{2}}{2 m_{\text {la }}} d t d t \\
x(0)=X_{\text {pre }} x\left(T_{\text {exit }}\right)=x_{\text {rail }}
\end{gathered}
$$

The model parameters of the kine-mechanical model are given in Table II. $\mathrm{L}_{\text {pr }}^{\prime}$ is calculated $0.515 \mu \mathrm{H} / \mathrm{m}$ from 3-D FE model using (10) and (11) where $\mathrm{V}_{\text {arm }}$ denoted as the volume of the armature.

$$
\begin{gathered}
\vec{F}_{p r}=\iiint_{V_{a r m}} \vec{J} \times \vec{B} d V \\
L_{p r}^{\prime}=\frac{2 F_{p r}}{I^{2}}
\end{gathered}
$$

TABLE II

THE MOdel PARAMETERS

\begin{tabular}{lc} 
Parameter & Value \\
\hline$C_{d}$ & 1 \\
$A_{l p}$ & $37.5 \mathrm{~cm}^{2}$ \\
$\rho_{\text {air }}$ & $1.225 \mathrm{~kg} / \mathrm{m}^{3}$ \\
$\mu_{d}$ & $0.3^{\dagger}$ \\
$\mu_{s}$ & $0.5^{\dagger}$ \\
$\zeta$ & -0.01 \\
$X_{\text {pre }}$ & $0.7 \mathrm{~m}$ \\
\hline
\end{tabular}

$\dagger \mu_{d}$, and $\mu_{s}$ are changing according to contact state.

\section{B. Control Method}

Aforementioned a control method where the proposed bus' inductance added is required to test the proposed model. In this subsection, features of the control method are discussed. Before the launch, the armature is located at the initial position called the pre-load distance. If the bus geometry is excluded, the EML uses geometry which is demonstrated in Fig. 6. Thus EML has an initial inductance denoted as $\mathrm{L}_{0}$ can be calculated using $L^{\prime}$ as the $\mathrm{L}_{0}$ is a portion of rails. Then total inductance of the system can be rewritten as (17). Then, the initial inductance can be calculated (18), excluding any electromagnetic effect from its surroundings as the containment is non-conductive. Moreover, the module currents enter rails from the surface, although their cables are connected to buses at different locations. As module cables, and their connections to the bus are not modeled implicitly, the complexity of the model is reduced.

$$
L(t)=L^{\prime}\left(x_{\text {arm }}(t)-X_{\text {pre }}\right)+L_{0}
$$

$$
L_{0}=X_{a r m} L^{\prime}
$$

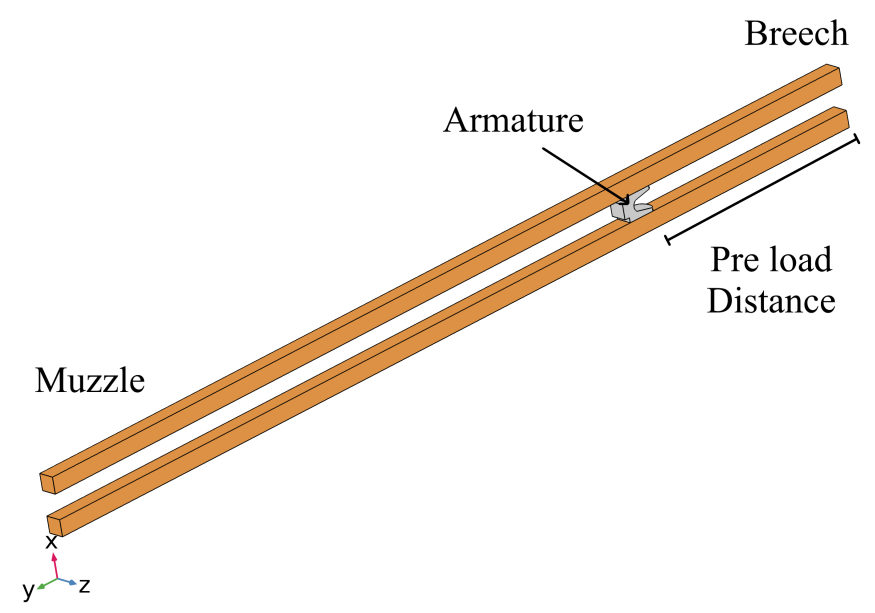

Fig. 6. The control group geometry.

\section{Proposed Method}

Unlike the control method, the proposed method takes the effect of the bus geometry. Coaxial cables are connected to the bus according to their module number. Thus, if there is any interaction between pre-load rail portion and bus geometry, 3-D FEM simulation should regard that aspect.

As each connection path introduce different has, so they should be added to the simulation model. The proposed model is illustrated in Fig. 7. $\mathrm{L}_{1}$ and $\mathrm{L}_{2}$ are used to model the difference in inductance paths. For example $\mathrm{PPS}_{1}$ connected behind to the $\mathrm{PPS}_{2}$ which can be seen in Fig. 8. For that reason, the $\mathrm{PPS}_{1}$ current flows through $\mathrm{L}_{1}+\mathrm{L}_{2}$, whereas $\mathrm{PPS}_{2}$ current flows through just $\mathrm{L}_{2}$.

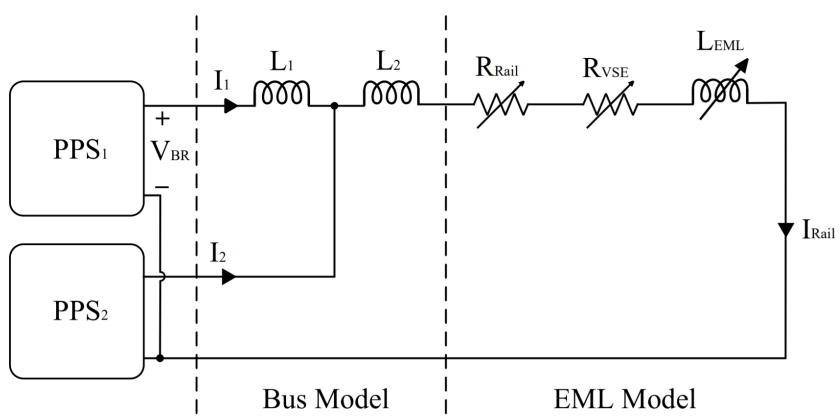

Fig. 7. The proposed EML model with seperate bus inductances. Breech and muzzle points are located.

A FEM model is developed to investigate the impact of the bus geometry. In that regard, a test scenario is simulated in 3-D 


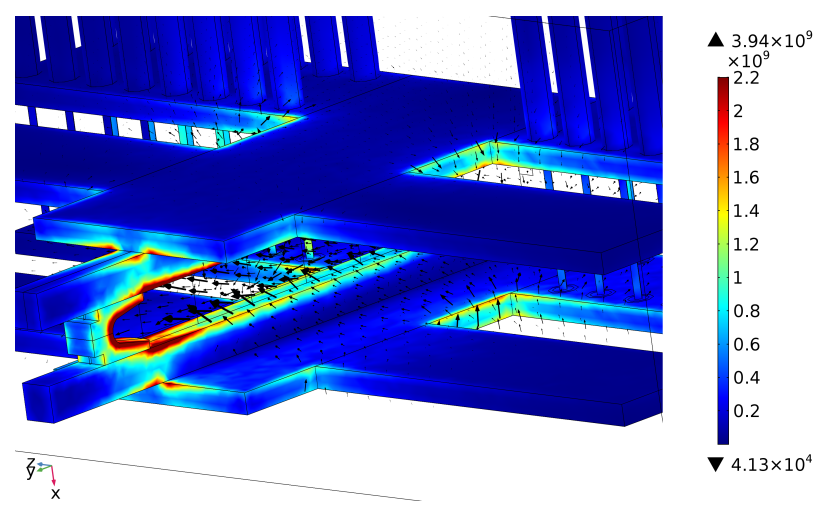

(a)

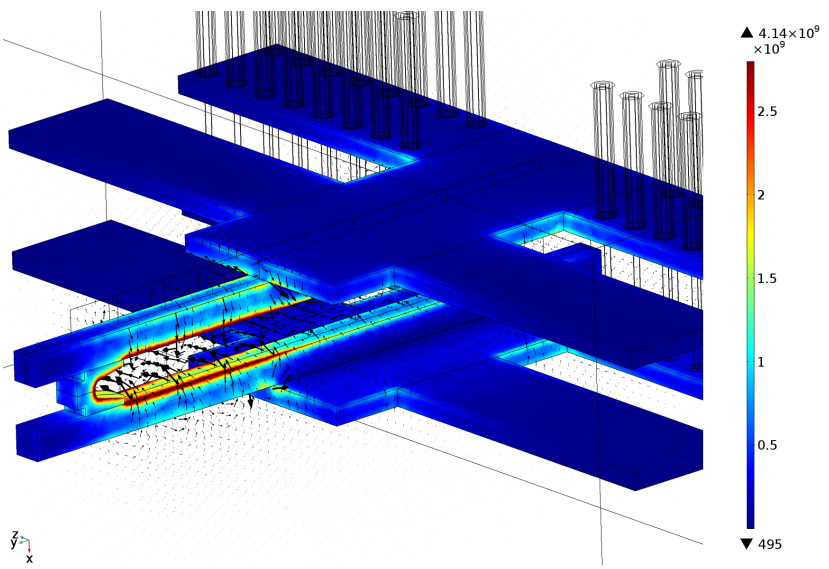

(b)

Fig. 8. Current density distribution and magnetic flux density vectors when the armature is located at its pre-load position (a), and ahead from its pre-load position (b). The color legend is for the current density only and its unit is $\mathrm{A} / \mathrm{m}^{2}$.

FEM. Since the armature geometry movement is not allowed in 3-D electromagnetic FEM, two different cases are solved. In the first case, the armature is located at the pre-load position as in Fig. 6. The current density distribution and the magnetic field density vectors are demonstrated in Fig. 8. a. The result showed that the magnetic field distribution is disturbed due to the bus geometry. In the first phase of the launch (0-1 ms), the rail current is in change, creating a time-varying magnetic field around rails. These varying fields can not diffuse the bus geometry since it is conductive. Eddy currents in the bus not only creates an additional loss but also reduce $L_{0}$ as they block rail's magnetic field.

The armature is moved from its pre-load position by $30 \mathrm{~cm}$ in the second phase, and electromagnetic analysis is repeated. Current density distribution and the magnetic flux density vectors are illustrated in Fig. 4,b. The rail portion ahead of the bus creates a larger magnetic field than the rail portion, which interacts with the bus. Thus, when the armature starts to move, the inductance contribution is larger than the inductance due to its initial position. This results showed that (18) can not be used to model $\mathrm{L}_{0}$. $\mathrm{L}_{0}$ should be decomposed into $\mathrm{L}_{1}$ and $\mathrm{L}_{2}$, and they are examined in 3-D FEM.

\section{RESULTS}

In this part, the proposed model, which includes bus impact, and the control method, are compared with experimental results. Three launch results of the EMFY-3 launcher are represented. The proposed method regards improvements, whereas the control method is used to create a benchmark. Rail currents are measured with Rogowski coils, and the muzzle velocities of the launch package are measured by doppler radar.

As aforementioned, the aim is to create pulse shape rail current; thus, the triggering times are evaluated accordingly. Since these calculations is made with the control method, unexpected deviations occurred at the rail current waveforms. Three of them are illustrated in Fig. 9 with their expected reference levels. Test parameters of these launches are demonstrated in Table III. At the initial state $(0-1 \mathrm{~ms})$, rail currents overshot from their reference value, resulting in larger peak currents. This phenomenon occurred dominantly with larger rail currents.

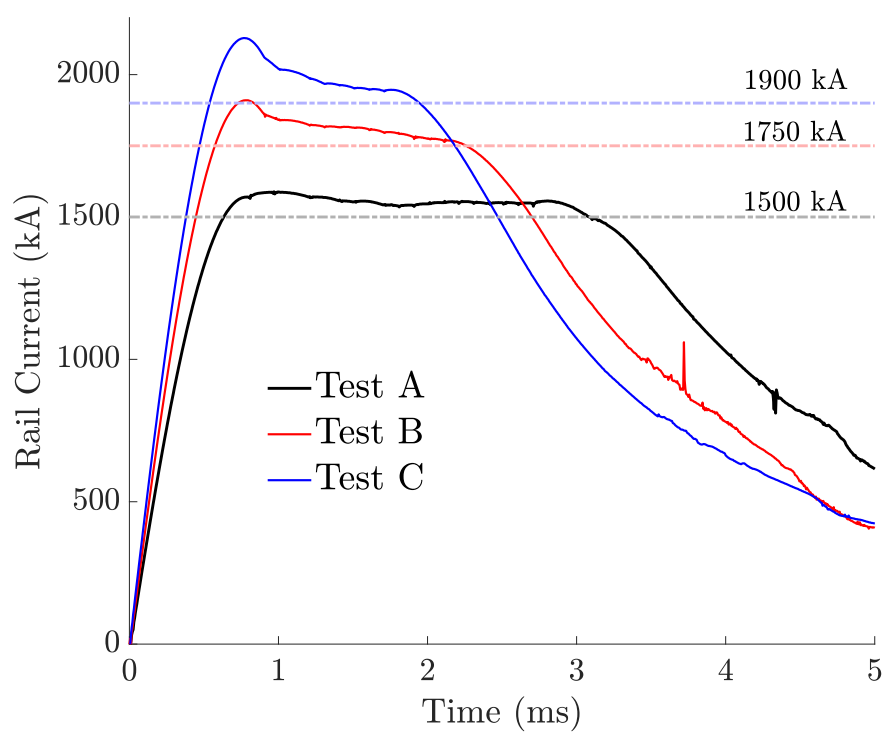

Fig. 9. Rail current measurements. Reference currents are indicated with dashed lines.

The simulation results of the control method, proposed method, experimental results, and improvement ratios (IR) are given in Table IV] The improvement ratio used to compare the two methods uses mean absolute error (MAE) measurements such as armature exit time, muzzle current, and muzzle speed. MAE and the IR are defined in (21) and (22) respectively where $\hat{\mathrm{x}}_{\text {control }}, \hat{\mathrm{x}}_{\text {proposed }}$ and $\mathrm{x}$ denote the simulated value of control method, the simulated value of the proposed method, and experimental result.

TABLE III

TEST PARAMETERS

\begin{tabular}{lcc} 
& Peak Rail Current & PPS Energy \\
\hline Test A & $1.58 \mathrm{MA}$ & $8 \mathrm{MJ}$ \\
Test B & $1.91 \mathrm{MA}$ & $8 \mathrm{MJ}$ \\
Test C & $2.12 \mathrm{MA}$ & $8 \mathrm{MJ}$
\end{tabular}

$M A E=|\hat{x}-x|$ 


$$
I R=\frac{M A E\left(\hat{x}_{\text {control }}, x\right)-M A E\left(\hat{x}_{\text {proposed }}, x\right)}{x}
$$

The simulated and experimental rail current waveforms and breech voltages are demonstrated for comparison in Fig. 10. Turquoise color is used to demonstrate the improved region. The peak current and the breech voltage waveform are improved in terms of accuracy in the improved region. As the bus impact will be diminished when the rail current is in DC, findings are consistent with theory. In Fig. 11, the simulated and experimental velocity curves are illustrated with three launches. The proposed method gives more consistent results with findings, whereas the control method underestimates the muzzle velocity. As both methods uses same kine-mechanical equations, and $\mathrm{L}_{\mathrm{pr}}^{\prime}$, the difference occurs due to rail current calculation errors. These errors are dependent the inductance variation of the EML. Thus, the proposed model provides more accurate results than the control method. Peak rail currents, and muzzle energies calculations improved $5.71 \%$, and $2.40 \%$ in average respectively.

\section{CONCLUSions}

The remarks obtained throughout the development of the simulation model and conducted experimental results can be listed as follows.

1) The proposed model improves the simulation accuracy, especially at the peak rail current.

2) The bus geometry affects the magnetic field distribution around the rail portion, which intersects. The lack of magnetic field diffusion reduces the related inductance, which increases peak rail current. The bus impact is dominant in the first phase of the launch, where the rail current is transient.

3) $\mathrm{L}_{0}$ can not be modeled as in (18) when PPS is connected with large buses. A detailed electromagnetic 3-D FEM is required to calculate.

4) When multiple PPS are used to excite one EML, every inductance path is important and should be analyzed. The proposed model can be useful for distributed energy supply (DES) to excite long EMLs.

\section{ACKNOWLEDGMENT}

The authors would like to thank Umut Tureli, and the other ASELSAN Team members whose support made this article possible.

\section{REFERENCES}

[1] E. Durna, Y. Çevik, M. Karagöz, and A. Civil, "Design and implementation of a hierarchical control system architecture for a modular pulsed power supply system," in 2016 IEEE International Power Modulator and High Voltage Conference (IPMHVC), 2016, pp. 594-597.

[2] A. Civil, Cavbozar, M. Karagöz, E. Tan, and Y. Çevik, "Design and improvement of a pulse shaping inductor for a pulsed power system," in 2017 IEEE 21st International Conference on Pulsed Power (PPC), 2017, pp. 1-3.

[3] M. Karagoz, Y. Çevik, E. Tan, A. Civil, O. Cavbozar, U. Gocmen, B. Yildirim, E. Durna, and M. Sahin, "Aselsan emfy-1 electromagnetic launcher: First experiments," in 2017 IEEE 21st International Conference on Pulsed Power (PPC), 2017, pp. 1-3.

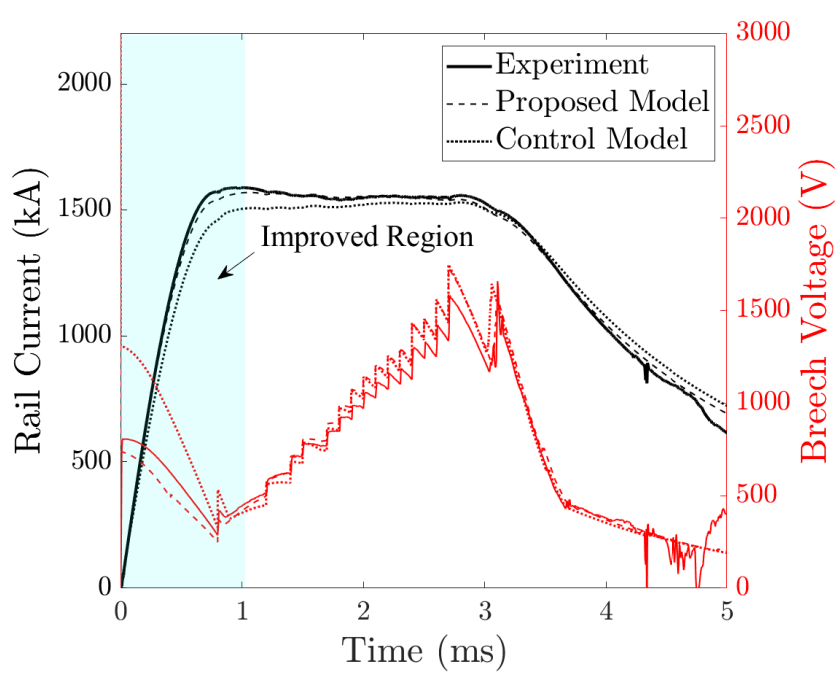

(a) Test $\mathrm{A}$

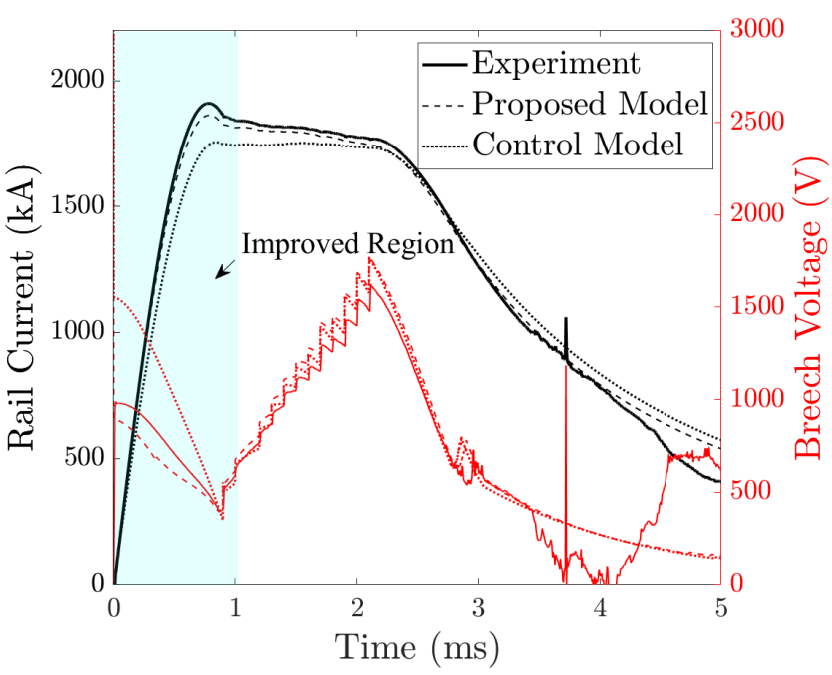

(b) Test B

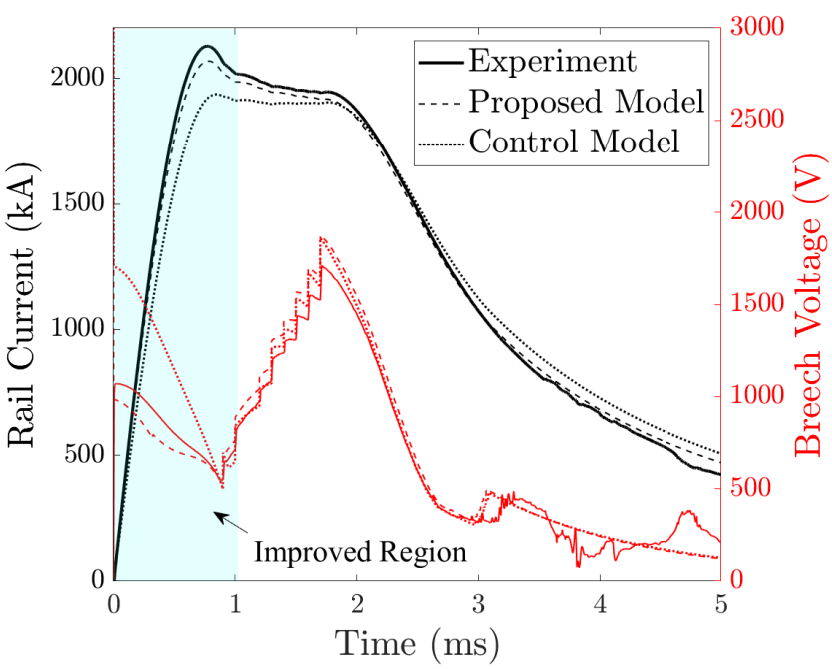

(c) Test $\mathrm{C}$

Fig. 10. Simulation and experimental results for the rail currents and breech voltages. 
TABLE IV

SOME CRitical OutPuts of THE EMFY-3 EXPERIMENTS AND Simulations With THE CONTROL AND PROPOSED METHODS

\begin{tabular}{|c|c|c|c|c|}
\hline & Proposed Method & Control Method & Experimental Result & Improvement $^{\mathbf{1}}$ \\
\hline \multicolumn{5}{|l|}{ Test A } \\
\hline Peak Rail Current & $1.56 \mathrm{MA}$ & $1.51 \mathrm{MA}$ & $1.59 \mathrm{MA}$ & $5.28 \%$ \\
\hline Muzzle Current & $0.80 \mathrm{MA}$ & $0.78 \mathrm{MA}$ & $0.81 \mathrm{MA}$ & $3.50 \%$ \\
\hline Muzzle Velocity & $2241 \mathrm{~m} / \mathrm{s}$ & $2186 \mathrm{~m} / \mathrm{s}$ & $2238 \mathrm{~m} / \mathrm{s}$ & $2.32 \%$ \\
\hline \multicolumn{5}{|l|}{ Test B } \\
\hline Peak Rail Current & $1.86 \mathrm{MA}$ & $1.75 \mathrm{MA}$ & $1.91 \mathrm{MA}$ & $5.65 \%$ \\
\hline Muzzle Current & $0.76 \mathrm{MA}$ & $0.74 \mathrm{MA}$ & $0.75 \mathrm{MA}$ & $1.12 \%$ \\
\hline Muzzle Velocity & $2354 \mathrm{~m} / \mathrm{s}$ & $2290 \mathrm{~m} / \mathrm{s}$ & $2312 \mathrm{~m} / \mathrm{s}$ & $-0.86 \%$ \\
\hline \multicolumn{5}{|l|}{ Test $\mathbf{C}$} \\
\hline Peak Rail Current & $2.07 \mathrm{MA}$ & $1.94 \mathrm{MA}$ & $2.13 \mathrm{MA}$ & $6.20 \%$ \\
\hline Muzzle Current & $0.75 \mathrm{MA}$ & $0.70 \mathrm{MA}$ & $0.74 \mathrm{MA}$ & $4.85 \%$ \\
\hline Muzzle Velocity & $2428 \mathrm{~m} / \mathrm{s}$ & $2357 \mathrm{~m} / \mathrm{s}$ & $2418 \mathrm{~m} / \mathrm{s}$ & $2.11 \%$ \\
\hline
\end{tabular}

${ }^{1}$ Improvement ratio is described at (18).

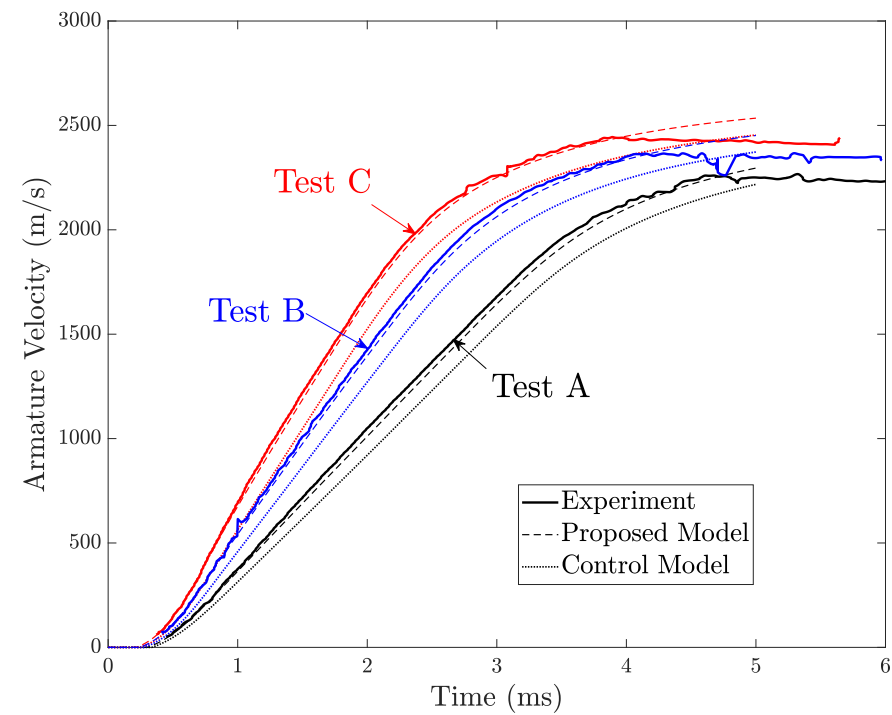

Fig. 11. Simulation and experimental results for the velocity curves.

[4] M. Karagoz, A. Civil, B. Yildirim, E. B. Yurdakul, E. Durna, E. Tan, O. Cavbozar, U. Gocmen, and Y. Cevik, "Aselsan electromagnetic launch laboratory: First shot," IEEE Transactions on Plasma Science, vol. 48, no. 4, pp. 802-807, 2020.

[5] D. Ceylan, M. Karagöz, Y. Çevik, B. Yıldırım, H. Polat, and O. Keysan, "Simulations and experiments of emfy-1 electromagnetic launcher," IEEE Transactions on Plasma Science, vol. 47, no. 7, pp. 3336-3343, 2019.

[6] N. Tosun, H. Polat, D. Ceylan, M. Karagoz, B. Yıldırım, Güngen, and O. Keysan, "A hybrid simulation model for electromagnetic launchers including the transient inductance and electromotive force," IEEE Transactions on Plasma Science, vol. 48, no. 9, pp. 3220-3228, 2020.

[7] N. Tosun, D. Ceylan, H. Polat, and O. Keysan, "A comparison of velocity skin effect modeling with 2-d transient and 3-d quasi-transient finite element methods," IEEE Transactions on Plasma Science, vol. 49, no. 4, pp. 1500-1507, 2021.

[10] N. Tosun, "Electromagnetic launcher speed control with a multilevel fast triggering time algorithm (mftta)," Sep 2020. [Online]. Available: https://www.techrxiv.org/articles/preprint/Electromagnetic_Launcher_
[8] H. Zhang, G. Cheng, W. Guo, Z. Su, and T. Zhang, "A lumped parameter model and its code for capacitor-based railgun with arbitrary number of pfus," IEEE Trans. Plasma Sci., vol. 42, no. 8, pp. 2098-2103, Aug 2014.

[9] H. Zhang, G. Cheng, W. Guo, Z. Su, T. Zhang, and Y. Yang, "Calculating timing sequence of capacitor-based railgun with given muzzle velocity," IEEE Trans. Plasma Sci., vol. 43, no. 9, pp. 3298-3303, Sep. 2015. Speed_Control_with_a_Multilevel_Fast_Triggering_Time_Algorithm_ MFTTA /13011512/1

[11] F. Deadrick, R. Hawke, and J. Scudder, "Magrac-a railgun simulation program," IEEE Trans. Magn., vol. 18, no. 1, pp. 94-104, January 1982.

[12] G. E. Rolader, L. D. Thornhill, J. H. Batteh, and J. J. Scanlon, "Electromagnetic gun circuit analysis code (egcac)," IEEE Trans. Magn., vol. 29, no. 1, pp. 499-504, Jan 1993.

[13] J. Wey, E. Spahn, and M. Lichtenberger, "Railgun modeling with the p-spice code," IEEE Trans. Magn., vol. 33, no. 1, pp. 619-624, Jan 1997.

[14] S. Tan, J. Lu, B. Li, Y. Zhang, and Y. Jiang, "A new finite-element method to deal with motion problem of electromagnetic rail launcher," IEEE Trans. Plasma Sci., vol. 45, no. 7, pp. 1374-1379, July 2017.

[15] K. . Hsieh and V. Thiagarajan, "A novel split-domain iteration scheme for solution of electromagnetic diffusion problems modeled by the hybrid finite-element-boundary-element formulation," IEEE Trans. Magn., vol. 45, no. 1, pp. 587-590, Jan 2009.

[16] P. Zuo, Y. Geng, J. Li, and J. Yuan, "An approach for eddy-current calculation in railguns based on the finite-element method," IEEE Trans. Plasma Sci., vol. 43, no. 5, pp. 1592-1596, May 2015.

[17] Q. hua Lin and B. ming Li, "Numerical simulation of interior ballistic process of railgun based on the multi-field coupled model," Defence Technology, vol. 12, no. 2, pp. 101 - 105, 2016, 2016 International Symposium on Ballistics. [Online]. Available: http://www.sciencedirect.com/science/article/pii/S2214914716000064

[18] S. Satapathy and H. Vanicek, "Down-slope contact transition in railguns," IEEE Transactions on Magnetics, vol. 43, no. 1, pp. 402-407, 2007.

[19] M. S. Bayati, A. Keshtkar, and A. Keshtkar, "Transition study of current distribution and maximum current density in railgun by 3-d fem-iem," IEEE Transactions on Plasma Science, vol. 39, no. 1, pp. 13-17, 2011.

[20] T. G. Engel, J. M. Neri, and M. J. Veracka, "Characterization of the velocity skin effect in the surface layer of a railgun sliding contact," IEEE Transactions on Magnetics, vol. 44, no. 7, pp. 1837-1844, 2008.

[21] J. Wu, G. Wan, N. Cheng, L. Li, and B. Li, "Research on armature's wearing and dynamic interior ballistic of a railgun," IEEE Transactions on Plasma Science, vol. 45, no. 7, pp. 1202-1207, 2017. 